\title{
Moving beyond (non-)compliance: the customization of European Union policies in 27 countries
}

This is the final version of:

Thomann, E. and A. Zhelyazkova. 2017. Moving beyond (non-)compliance: the customization of European Union policies in 27 countries. Journal of European Public Policy 24(9): 1269-1288.

\begin{abstract}
Europeanization research often neglects that the implementation of European Union (EU) policy results in diverse national outcomes, even if member states comply with EU law. Such fine-grained Europeanization patterns have been explored as 'gold-plating' and 'customization'. This paper builds and expands on this research to propose a general conceptualization and measurement of customization as the changes that provisions of EU Directives undergo in their regulatory density and restrictiveness during legal transposition. Using unique data on the customization of EU Directive provisions from two policy areas in 27 countries, our empirical analysis reveals distinct changes in density and restrictiveness, pronounced policy-specific and state-level customization patterns. The findings illustrate how national customization strategies often follow specific EU regulatory logics in different integration contexts. We outline implications for future research on the causes and consequences of the inherent diversity of EU implementation regarding dimensions of customization, issues of legitimacy and effectiveness.
\end{abstract}

Keywords: Compliance, Customization, Europeanization, European Union, gold-plating, multi-level implementation 


\section{Introduction}

This paper lays the conceptual basis for systematic comparative research on the 'customization' of European Union (EU) policy, and explores empirical customization patterns across member states and policy sectors. Multi-level governance systems calibrate legal and economic integration with member state discretion in implementation (Hooghe and Marks 2003; Majone 1999; Windhoff-Héritier 2001). In Europeanization research, this discretion has mainly been studied in terms of legal compliance (Treib 2014). Yet case study evidence suggests that even the compliant implementation of EU policy entails divergent national outcomes, frequently as a result of high levels of EU policy ambiguity (e.g., Falkner et al. 2005; Shapiro 1999; Versluis 2003). Such differences co-exist with incentives of national authorities to comply with the EU Directives (Mastenbroek 2017 <THIS ISSUE: $\begin{array}{llll}\text { PUBLISHER TO ADD } & \text { /UPDATE }\end{array}$ DETAILS AT PROOF>; Steunenberg 2007).

Consider how the EU guarantees that motor vehicles are properly checked and maintained while in use (Davidson 2006: 23-25). Council Directive 91/328/EC requires a roadworthiness test to be carried out every other year from the car's fourth year onwards. However, the Directive allows for bringing forward the date of the first test, and /or shortening the interval between two successive tests. As to 2006, member states complied with this EU rule in strikingly diverse ways. Only nine out of 25 countries transposed the EU rule literally. 14 member states required an earlier first inspection; and ten countries, annual follow-up inspections. Car owners face very differing demands, depending on how the respective country interprets the EU rule. Research on 'gold-plating' and 'customization' (Thomann 2015) scrutinizes such interpretations.

However, we know remarkably little about the extent, reasons and implications of this finegrained diversity in EU implementation (Thomann and Sager 2017 <THIS ISSUE: 
PUBLISHER TO ADD /UPDATE DETAILS AT PROOF>. This is unfortunate for three intertwined reasons. First, national authorities strive to avoid infringement costs while choosing the most appropriate strategies to implement EU policies (Steunenberg 2007). These strategies have potentially far-reaching implications for how common policy problems are resolved in practice in the EU (Scharpf 1997), but go unnoticed by analyzing legal compliance. Second, a growing body of evidence suggests that under certain circumstances, legal compliance with EU law may be unrelated to its practical application (Falkner et al. 2005; Versluis 2003, 2007; Zhelyazkova et al., 2016). Therefore, third, studying legal compliance without considering adaptations of EU policy to domestic circumstances provides an incomplete picture of EU implementation. Yet, conceptual and empirical obstacles have hindered the accumulation of systematic, cumulative knowledge on this phenomenon.

Conceptually, diversity in EU transposition has primarily been linked with issues of noncompliance and unintended competitive distortions (e.g., Davidson 2006; Jans et al. 2009; Morris 2011; Voermans 2009). Thomann (2015) then proposed a more fine-grained conceptualization of member states' customization of the density and restrictiveness of EU rules. We build on this earlier work to refine and generalize the customization concept in three ways: First, we assume that customization is a phenomenon of vertical regulatory change irrespective of (non-)compliance. Second, different aims and manifestations of EU law in contexts of positive and negative integration allow for different directions of change (Lowi 1972; Scharpf 1997; Vink 2002). Third, we link the concept more explicitly to the regulatory output literature to specify the meaning, distinctness and interrelation of the two dimensions of change, density and restrictiveness (Adam et al. 2015; Bauer and Knill 2014; Knill et al. 2012; Schaffrin et al. 2015).

Empirically, existing knowledge on these phenomena is still limited to a few case studies of selected policies and countries. Without broader comparative studies, the empirical relevance 
of these insights and their contingency upon selection bias, sectoral and national specificities remain unclear (Angelova et al. 2012; Toshkov 2010; Treib 2014). To remedy such biases and enable cumulative research, we propose a comprehensive and differentiated scheme to measure customization. Applying a subset of the proposed comprehensive conceptualization, we ask: What empirical customization patterns do we observe across EU member states and policy areas? What is the relationship between different dimensions of customization? We scrutinize how 27 member states customize separate provisions from 31 EU Directives from two policy areas: Justice and Home Affairs (JHA) (10) and Environment (21).

This descriptive and explorative analysis illustrates pronounced policy-specific differences in customization that often conform to EU regulatory logics. Furthermore, our study shows that the relationship between different dimensions of customization differs across policy areas: the number of rules added to or taken away from an EU requirement (customized density) may not necessarily tell us about more substantive changes of EU policies through levels of restrictiveness in national legislation. Previous research has neglected this distinction. Next, we discuss the conceptualization and measurement of customization. After introducing the data and methods, we present and discuss our results. We outline theoretical implications and trajectories for future research.

\section{Understanding diversity in multi-level implementation}

Europeanization scholars highlight that the inherent ambiguity of EU rules result in different degrees of flexibility and legal uncertainty, leading to different interpretations by member states and implying that implementation is dominated by national politics (Schmidt 2008; Windhoff-Héritier 2001). Additionally, relatively long-lasting policy, regulatory or administrative traditions or styles 'predispose [countries] to formulate and implement public policies in certain distinct ways' (Adam et al. 2015: 2; Richardson et al. 1982). 
These concepts resonated in Europeanization research, for example, as 'worlds of compliance' (Falkner et al. 2005) and non-literal interpretations of EU law (Steunenberg 2007). Situations when member states go beyond the minimum requirements of EU law have been referred to as voluntary over-implementation (Falkner et al. 2005) or gold-plating. Goldplating denotes all instances

'when implementation goes beyond the minimum necessary to comply with a Directive, by:

- extending the scope, adding in some way to the substantive requirement, or

- substituting wider domestic legal terms for those used in the Directive; or

- not taking full advantage of any derogations which keep requirements to a minimum (e.g. for certain scales of operation, or specific activities); or

- providing sanctions, enforcement mechanisms and matters such as burden of proof which go beyond the minimum needed (e.g. as a result of picking up the existing criminal sanctions in that area); or

- implementing early, before the date given in the Directive' (Voermans 2009: 8).

Only few case studies have addressed this phenomenon, suggesting that countries have different approaches toward gold-plating. For example, the UK and Spain are rather literal transposers, while the Netherlands sometimes add extra rules (Davidson 2006; Lugt 1999: 132; Versluis 2003: 17, 19). Tendencies toward over-implementation were found in the power sector in Germany and Sweden (Padgett 2003) and regarding social policies in certain old and new member states (Falkner et al. 2005). The Netherlands and the UK rarely engage in the gold-plating of environmental Directives (Jans et al. 2009; Morris 2011; Voermans 2009). The literature often treats gold-plating as a potentially problematic transposition outcome that can conflict with compliance (Mastenbroek 2005), associated with red tape 'resulting in unnecessary burdens and competitive disadvantages for domestic businesses' (Voermans 2009: 8; see also Davidson 2006). However, this view 'insufficiently captures the implications of member states being part of a multi-level system' (Schmidt 2008: 299). 
Thomann (2015: 1370) proposes to think of EU member states as problem-solvers who use their leeway to adapt - that is, customize - EU rules to local contexts. While building on the gold-plating concept, Thomann (2015) seeks to separate the question of diversity in implementation from questions of non-compliance. Therefore, she analyzes only cases of correct transposition, where compliant member states go beyond market-correcting EU minimal standards. Moreover, she uses the concrete categories that have been fruitfully applied to measure changes of regulatory, (re-)distributive, and morality policies (Adam et al. 2015; Bauer and Knill 2014; Knill et al. 2012; Schaffrin et al. 2015). These changes occur on two distinct, although typically interrelated dimensions, namely regarding the amount of rules (density) and their content (intensity). Hence, Thomann refines the gold-plating notion by accounting for degrees to which the domestic regulations complement an EU rule with more or stricter rules than required, and adding these into a combined customization index. Goldplating scholars have not clearly distinguished these two change dimensions: some, like Versluis (2003: 48), emphasize the 'adding of extra requirements' (density), whereas others like Lugt (1999: 132) emphasize 'the laying down of stricter requirements' (stringency).Yet, as we illustrate below, the two dimensions of density and restrictiveness illuminate countries' distinct customization strategies. For example, the UK often added exemptions to EU food safety rules (customized density) to maintain regulations that remain as liberal as possible (no customized restrictiveness) (Thomann 2015).

However, previous studies may exaggerate idiosyncratic country differences, by often focusing on only one policy area (Treib 2014). Member states could exhibit completely different transposition patterns regarding other policies. How exactly these changes occur across a wider range of policies and countries remains unclear. To enable systematic cumulative research on the phenomenon, we now refine and generalize the definition of customization. 


\section{How do EU rules change during transposition?}

Thomann's (2015) customization concept presupposes compliant transposition. Note however that customization and compliance are two distinct phenomena: the tailoring of rules to local circumstances may occur within the scope of discretion granted by an EU rule (compliance), or outside (noncompliance). Which is the focus of analysis hinges on the specific research interest. Furthermore, the requirement of assessing member states' compliance first may unnecessarily complicate the measurement of customization. Especially ambiguous EU provisions do not provide a clear yardstick defining (non-)compliant behavior (Schmidt 2008), so 'differences in degree' may more adequately capture varying responses. But even if Directives contain very clear yardsticks, establishing compliance may be a contentious process. Confining the analysis to instances of clear-cut compliance may hence result in a loss of substantively interesting and important cases of customization

Furthermore, previous studies refer to situations when member states add to EU provisions. Indeed, often domestic rules go beyond the necessary minimum set out by EU rules, especially when these aim at positive integration to correct common market problems - such as the safety of motor vehicles - through (re)regulation (Vink 2002: 3). While countries have to regulate at least as much as the EU prescribes, more ambitious domestic policies - for example, more frequent roadworthiness tests - help correct the problem (Jans et al. 2009; Scharpf 1996). However, implementers adapt non-standardizing EU rules in differing directions, depending on their specific nature and purpose. Particularly in contexts of negative integration, EU rules often set out a regulatory limit that member states must not exceed (Scharpf 1996). Such rules may serve to avoid restrictions of freedoms or rights or distortions of the common market, such as barriers to trade (Vink 2002: 2). Customized domestic rules that go below the EU provision, for example lower tariffs than allowed by the EU, can result from a regulatory 'race to the bottom'. Many EU rules also provide a range of acceptable 
regulation (Steunenberg 2007). For example, EU copyright legislation provides a 'menu' of exemptions to the limits of reproduction rights of right-holders. National legislators should at very least allow 'temporary acts of reproduction'; beyond the defined range of possible exemptions, they also cannot include additional exemptions. However, this ideal-typical distinction is often not clear-cut in practice especially for ambiguous EU rules, and does not necessarily correlate with positive or negative integration contexts (Scharpf 1997: 522; Schmidt 2008). Researchers should therefore always explicitly account for situations in which transposing countries both add to or take away from EU rules.

Finally, the existing toolbox to measure regulatory change highlights the relevance of the two dimensions of density and restrictiveness. Schaffrin et al. (2015) differentiate changes in policy outputs according to six substantive categories: objectives, scope, integration, budget, implementation, and monitoring. Overall customization patterns consist of the extent of the changes in these categories of EU rules along the two dimensions of density and restrictiveness. An aggregated customization index may add up the values (Thomann 2015) or calculate their average, where larger deviations both in positive or negative directions indicate more extensive customization levels. Yet distinguishing the two dimensions is not obsolete. Although they are logically connected, they refer to distinct aspects of state action and illuminate a differentiation of variation in national adaptation strategies that can be insightful (Knill et al. 2012). So far, the implications of the distinctness and interrelation of these dimensions for understanding the differences in the national transposition of EU legislation have not been studied systematically.

Regulatory density tells us about the formal extent and breadth to which governmental activities address a certain policy area. It captures the amount of government activity, as one aspect of government size and growth (Bauer and Knill 2014). Customized density refers to changes in the degree of regulatory penetration, complexity and internal differentiation (Knill 
et al. 2012). Member states may or may not apply optional EU rules, concretize, amend, differentiate or specify exemptions to especially broadly formulated EU rules. Often, more customized density leads to more restrictive rules. However, sometimes the opposite happens. For example, the Directive 2003/4/EC allows member states to refuse public access to environmental information if such disclosure would adversely affect intellectual property rights. Yet Slovenia specifies that intellectual property rights is not a ground for refusal (less restrictive) by adding that the applicant can still review a copy of the requested information (more density than the EU provision).

This example shows that simply counting outputs may not do adequate justice to the content of rules, which can be adapted in its intensity. Customized restrictiveness captures how EU rules are changed in the scope and level of state intervention to influence target group behavior through the extent of the substantial freedom left to policy addressees or the generosity of the services or resources provided (Bauer and Knill 2014: 33; Knill et al. 2012: 430; Schaffrin et al. 2015). ${ }^{1}$ This dimension reflects different answers of member states to 'the question of how to resolve the tension between citizens' individual freedoms and public intervention in order to reach political goals' (Adam et al. 2015: 19). Depending on the importance or significance governments attach to certain measures, domestic rules represent a tightening (adds restrictiveness) or loosening (removes restrictiveness) of the EU rules. For instance, we have seen that member states added different degrees of restrictiveness to the EU's roadworthiness test requirement to ensure the continued safety of motor vehicles. Restrictiveness also captures different state traditions representing deeply institutionalized norms specifying the relationship between state and society. Liberal member states generally tend to minimally intervene into individual and collective freedom, while others are traditionally more interventionist (Adam et al. 2015; Richardson et al. 1982). For example, Germany adopts a regulatory strategy to reduce antibiotic resistance through severe 
restrictions of the use of antibiotics for livestock; conversely, the UK has more lenient rules and resorts to private self-regulation and codes of good practice instead (Thomann 2015).

Increases in density often imply increases in restrictiveness, and vice versa. For instance, unlike Directive 2003/35/EC, Latvian law does not limit the scope of the public entitled to challenge decisions related to public participation in environmental plans and programs (less density). Any natural and legal entity has the right to challenge a respective decision (less restrictiveness). Changes in one dimension usually affects the other - but not inherently in the same direction. For example, many member states adopted less restrictive conditions for acquisition of European Community (EC) long-term resident status than minimally required by Directive 2003/109/EC (less restrictiveness). Doing so also entailed defining the categories of persons to which these conditions should apply (more density). Nevertheless, member states' transposition outcomes were still more favorable to EU refugees than the EU directive. While modifications in density may increase or decrease levels of restrictiveness, they can also serve definitional or other purposes, such as concretizing EU rules to enhance legal certainty, or integrating the particular concerns of specific interest groups.

Our main point is that by only focusing on one of the two dimensions or simply merging them, one may miss interesting variation (Schaffrin et al. 2015). By analogy, body size and weight are also closely interconnected. Nonetheless, only by looking at both can we make meaningful comparisons of people's physical appearance. While their relevance and implications for customization is subject to future research, the two dimensions have proven useful for describing policy change (Bauer and Knill 2014; Knill et al. 2012) and regulatory styles (Adam et al. 2015).

We thus expand and refine existing concepts and define customization as the changes that EU rules undergo in their density and restrictiveness during legal transposition independent from assessments of (non-)compliance, along the different categories of policy content (objectives, 
scope, integration, budget, implementation, and monitoring) and the dimensions of density (formal) and restrictiveness (content). This definition includes scenarios of transposing rules adding to or removing density or restrictiveness from an EU provision.

\section{Measuring customization}

Figure A1, online appendix, resumes our proposed conceptualization and measurement of customization, which can be adopted partly or fully to fit any specific research setting. We apply a subset of the scheme for comparing customization across 27 member states (excluding Croatia) and two policy areas: Justice and Home Affairs (10 Directives) and Environment (21 Directives).

\section{Data}

The EU Commission sometimes mandates legal experts to craft evaluation or monitoring reports that can be used as secondary data sources (Mastenbroek et al. 2016). Our own analysis uses conformity reports that share the same structure and contain so-called concordance tables (TOCs) that include the Directive provision, the domestic transposition measure, and an explicit evaluation of the latter's level of conformity by a national legal expert (see Tables A1-A3, online appendix). While prepared for assessing compliance, these expert assessments also provide invaluable information about customization and gold-plating. The experts discussed the detailed nature of transposition outcomes and whether these 'went beyond' the requirements of the Directive.

\section{Casing}

Domestic regulations of single EU provisions constitute the relevant units of analysis for customization (Zhelyazkova 2013). Relevant provisions can be identified by stakeholders and experts (Thomann 2015), or as single paragraphs of articles of an EU Directive (Franchino 
2007: 109). TOCs, as used here, provide a pre-determined separation of articles and subarticles. In decentralized countries, customization occurs into both national and sub-national legislation. EU rules differ widely in their relevance, length and substantial richness, and might hence have to be weighted according to these criteria (Toshkov 2010). To partly remedy this issue, this study includes only substantive provisions that required implementation and have implications for the national legislation and administrative practice.

\section{Measurement}

Establishing degrees and directions of customization becomes particularly challenging as ambiguous EU rules do not establish clear benchmarks (Schmidt 2008). Comparing the wording of the EU and transposing provisions is highly time and resource intensive. Instead we closely scrutinized and matched the expert evaluations of each provision to the two customization dimensions. Our sample hence only includes those state-provision dyads that contain explicit expert evaluations about customization. This procedure pragmatically addresses the issue of ambiguity, but excludes those provisions that are so broad or unclear that evaluating customization is difficult. Conformity assessments hence systematically under-represent the actual extent of customization. Expert evaluations with no information about customization do not imply equivalent transposition of the EU provisions. The legal expert may not have reported minor cases of customization particularly with compliant national measures. Hence, the set of cases of customization captured by our analysis is neither complete nor representative. Therefore, we can only compare relative customization levels across member states and policy areas. Yet we can still explore the relationship between the dimensions of density and restrictiveness across member states and issue areas.

Customized density refers to the amount/ number of rules (policies and/or instruments) that are added to or removed from the EU provision (e.g., scope restrictions, concretizations, 
requirements, conditions, exemptions or specifications added or taken away). In our analysis, a domestic transposing rule customizes the Directive provision with more density, if it adds at least one element to the latter. Alternatively, a member state may remove density by omitting an element of or not transposing an EU provision. We counted the times that an expert mentioned an addition to (coded as 1) or an omission (coded as -1) from a specific EU provision. Density levels range between -2 and 4 .

Customized restrictiveness occurs along an instrument's personal, substantive and/or temporal scope of application. The personal scope depicts the types of individuals or organizations addressed. Customized restrictiveness here indicates that a domestic requirement or restriction is valid for a larger target group than the EU provision; or that a freedom, resource or service is granted to a smaller set of addressees. The substantive scope refers to the activities (behavioral boundaries, cases, constellations, services, resources) covered by an instrument (Knill et al. 2012: 429, 431). More restrictive instruments seek to minimize certain behaviors, resources or services, or prescribe requirements that considerably limit individual freedom, as compared to the EU provision (Adam et al. 2015: 6). In temporal terms, activities, services or resources can be restricted to, granted or required for longer or shorter time periods.

The experts' evaluations do not distinguish the three levels of scope or assess degrees of customized restrictiveness. Instead, we relied on expert assessments that identified transposition outcomes as either more restrictive (coded as 1$)$ or less restrictive (-1; hence, more favorable to the relevant addresses) than the respective EU provision. For example, the experts mentioned that some member states implemented more flexible requirements for asylum applications or granted more rights to refugees (e.g., healthcare exceeding emergency cases). Other member states requested additional documents for asylum applications or further restricted refugees' rights relative to the JHA Directives. Customized restrictiveness amounts to 0 , if a provision was neither assessed as more restrictive nor as less restrictive than 
the EU provision. The most obvious manifestation of limited customization is literal or identical (equivalent) transposition. Note that customization can also result from non-changes in domestic policies (Bauer and Knill 2014: 33; Thomann 2015: 1370). In this case, differences between the EU and the domestic rule are decisive.

\section{Results}

Comparing transposition in 27 member states across two policy areas facilitates a comprehensive assessment of customization patterns. The JHA Directives define the conditions for obtaining a refugee status, the treatment of third-country nationals (TCNs) and their families. Many of these often controversial JHA provisions do not allow for more restrictive conditions that lower the standards for TCNs or refugees residing in the EU. Instead, the environment Directives impose technical requirements regarding, for example, emissions trading and environmental assessments of waste management plans. These EU environmental rules frequently restrict the behavior of sellers, producers, consumers, etc. and allow the member states to impose stricter conditions on domestic products.

After excluding all missing cases, our data-set contains 750 and 894 observations regarding member-state customization of specific EU provisions for JHA and Environment Directives respectively $^{2}$. 14 per cent of the latter 894 provision-state dyads represent subnational transposition. As customization hence varied within Belgium, the UK, and some regions in Spain, Austria and Finland, the number of observations in environmental policy is higher than in JHA policy, despite the lower number of assessed provisions.

Figure 1 presents the average member-state differences in customized restrictiveness and density, separately for JHA and environment EU provisions. The figure indicates significant differences in customization across the two policy areas that follow the regulatory logic of the EU policy. Most member states transposed JHA provisions less restrictively than prescribed 
by the EU Directives (74 per cent of the observations). For example, provision 27(2) of Directive 2004/83/EC requires that member states treat refugees in the same way as other TCNs. Beyond that, countries like Bulgaria, Finland, Hungary, Ireland, Poland and Sweden grant adults with refugee or subsidiary protection status access to the general education system under the same conditions as nationals. Denmark is the only exception. Even though it generally participates in Schengen legislation, general unwillingness to abandon its restrictive immigration policy made Denmark opt out of Amsterdam's Title IV provisions covering free movement, immigration and asylum. While we do not analyze the rationale behind member states' consistent tendencies to transpose immigration Directives less restrictively here, note that these decisions were taken prior to the recent refugee crisis.

\section{-- Figure 1 --}

Conversely, the transposition of Environment Directives - typical for positive integration - is on average more restrictive for sellers, producers, and the public than what the EU requires (63 per cent of all assessed cases). For example, article 9(2) of Directive 2001/18/EC mandates member states to make all information about releases of genetically modified organisms (GMOs) publicly available. Italy included an additional obligation for those who cultivate GMOs to install adequate cartels clearly indicating the presence of GMOs. Slovenia's flexible transposition of Directive 2003/4/EC is an exception: it loosens the EU's conditions for publicly requesting and receiving environmental data, even if such information is protected by intellectual property rights.

In short, customization appears to be largely driven by the nature of the EU provisions and the direction of flexibility they allow for. By contrast, customized density does not exhibit pronounced cross-country or policy-specific differences. The member states included 
additional rules to 28 per cent of the JHA policies, and to 48 per cent of the EU environmental provisions. Only very rarely did member states remove rules from Environment Directives.

Rather than pragmatically focusing only on the density or the restrictiveness dimension or simply combining them into one index, we seek to gain a fuller understanding about the relationship between these two aspects of customization (see Figure A2, online appendix). We find a strong positive relationship between customized restrictiveness and density in the JHA area, where restrictiveness is often removed from EU provisions by reducing the amount of rules during transposition (97 per cent of all cases reducing density; Pearson $r=.49$ ). To facilitate a favorable treatment of refugees, many EU member states chose not to transpose exemptions that would impose stricter requirements for obtaining refugee status. Article 17(3) of Directive 2004/83/EC, for instance, allows the member states to exclude a TCN or a stateless person from being eligible for subsidiary protection, if that person has committed one or more crimes prior to admission to the member state. Austria, Belgium, Cyprus, Finland, France, Germany, Greece, Hungary, Italy, Lithuania, Netherlands, Portugal and Romania did not transpose this provision (less density, less restrictiveness). Sometimes, density and restrictiveness were also added. While Directive 2001/51/EC provides alternatives for financial penalties on carriers transporting illegal immigrants, Poland and Spain even introduced all three alternatives (more density), making national provision more restrictive for carriers.

Conversely, there is no significant relationship between density and restrictiveness in the Environment sector (Pearson $\mathrm{r}=-. .04)$. Whereas member states included additional rules to EU provisions, many of them were neither more nor less restrictive than the EU provisions (44 per cent of cases with increased density). For example, Flanders (Belgium) transposed Directive 2004/3/EC on public access to environmental information by adding that 'information officers' should be designated. This concretization does not necessarily affect 
levels of restrictions to obtaining access to environmental information. Furthermore, in 73 percent of the cases in which the member states removed rules from an EU provision, national transposition was more, rather than less, restrictive than the EU requirements. For example, Directive 2000/76/EC on the incineration of waste specified that the emission limit value for nitrogen oxides does not apply to plants only co-incinerating hazardous waste until 1 January 2007. Hungary, however, did not transpose this exemption (less density). This rendered the Hungarian provision more stringent than the EU provision, as the emission limits apply immediately.

In sum, the relationship between restrictiveness and density varies across policy areas. Whereas the two dimensions co-vary in JHA policy, adding more rules is not associated with more restrictive outcomes in environmental policy. This suggests that information about customized density is not sufficient to understand domestic alterations of EU provisions. Even in the JHA area the relationship is not perfect. Directive 2001/51/EC, for instance, requires that member states ensure penalties to carriers of illegal immigrants. Art. 4(2) specifies that this requirement should not interfere with member states' obligations in cases where a third country national seeks international protection. However, Italy, Malta, the Netherlands, Portugal, Romania and Slovenia did not transpose this provision (less density), such that sanctions are applied regardless of whether asylum is sought or granted (more restrictive to carriers). In other cases, density was added to remove restrictiveness. For example, going beyond Art. 15 (1)(a) of Directive 2001/55/EC, the Czech legislation explicitly allows family reunification of a parent of a minor under 18 (more density, less restrictiveness).

These findings imply that patterns of customized restrictiveness relatively consistently follow the direction of flexibility indicated by EU legislation. Only by specifying 'what' - density or restrictiveness - was added to or taken away from the EU provision, do we adequately understand these interpretations. Thus, Figure 1 reveals differences that remain hidden when 
combining both dimensions into one customization index, as country-level density and restrictiveness could sometimes go in the opposite direction.

Whereas regulatory change could lead to non-compliance with EU rules, many of the instances of customization reported by experts also occurred when transposition was compliant (Figure A4, online appendix). We therefore 'zoom in' to consider the divergence of only those adaptations that met the EU requirements. Figure 2 compares the average levels and variation of compliant customized restrictiveness across member states for both policy areas (see Figure A5, online appendix for customized density).

-- Figure 2 -

The analysis reveals the considerable diversity of compliant transposition in the EU that remains hidden by only distinguishing (non-)compliance. For example, Bulgaria, Austria, the Czech Republic and France transposed the EU Environment provisions significantly more restrictively than other countries such as Slovenia, Portugal, Latvia and Belgium. Although the country differences are less pronounced in the JHA area, Cyprus, Ireland, Luxembourg and Romania generally transposed the EU provisions less restrictively relative to most other member states. In short, customization patterns do vary significantly across compliant member states. Yet national authorities respond differently to EU requirements depending on the policy sector. These patterns could indicate that domestic politics matter more for customization than country-specific transposition styles.

\section{Discussion}

In several respects, this study significantly enhances our knowledge about the diversity of 
transposition outcomes beyond legal compliance in the EU (Schmidt 2008). Building on earlier work on gold-plating and Thomann (2015), we have proposed a general but flexible conceptualization and measurement scheme that can travel across contexts to guide systematic comparative research on the customization of EU Directives. By partly applying the scheme to the transposition of EU Directives in two policy areas and 27 member states, this study paints the very first comprehensive - although descriptive and broad - picture of customization in the EU. Our large-N data-set differentiates neither different substantive categories of regulatory change, scopes of application nor degrees of customized restrictiveness on a continuous scale (Schaffrin et al. 2015). Relying on expert evaluations limited the scope of our results and made it impossible to identify absolute levels of customization. An internally more valid analysis requires considerable case knowledge and implies relatively high costs for data collection and coding (Adcock and Collier 2001; Hartlapp and Falkner 2009; Mastenbroek et al. 2016). Future research should comprehensively address the analytic challenge of identifying customization in face of legal ambiguity. When EU rules are very ambiguous, it might make more sense to compare countries' implementation with each other, rather than against an EU template (e.g., Sager et al. 2014). The results nonetheless provide preliminary, but solid evidence for the added value of analyzing customization.

Systematically distinguishing customized density and restrictiveness and allowing for different directions in which EU rules are changed helped us to illuminate different strategies of how member states interpret EU provisions, and the remarkable extent to which these adaptations follow sectoral EU regulatory logics. Contrary to previous case studies, our large$\mathrm{N}$ comparison does not conclusively indicate distinct country-specific styles of gold-plating or customizing EU Directives (Falkner et al. 2005; Jans et al. 2009; Morris 2011; Thomann 2015; Versluis 2003; Voermans 2009). Rather, pronounced policy-specific differences and 
domestic politics seem to characterize customization patterns - which resonates with compliance findings (Steunenberg 2007; Treib 2014). Depending on the nature and purpose of EU policies, member states not only add, but sometimes also remove density and/or restrictiveness from EU provisions. Accordingly, we find that member states often provide less restrictive conditions to TCNs than those defined in JHA Directives. Instead, environmental Directives are routinely customized to further restrict the behavior of target groups.

Findings also suggest that member states simultaneously strive to achieve compliance, and adapt EU policies to their local contexts. The resulting diversity in compliant transposition remains concealed when only looking at legal compliance. Moving beyond legal compliance to account for the customization of EU Directives therefore obviously provides substantive complementary insights into the diversity of transposition outcomes. But why should we bother about this diversity anyway?

\section{Conclusions: Implications for Europeanization research}

EU implementation patterns beyond legal compliance are to a large extent unknown territory (Heidbreder 2017 <THIS ISSUE: PUBLISHER TO ADD /UPDATE DETAILS AT PROOF>; Treib 2014). Reducing discretionary deviations from centrally decided provisions to a control problem neglects bottom-up views emphasizing that local implementers' closeness to the source of the policy problem enhances their ability to achieve policy success (Elmore 1979; Knill and Tosun 2012). Member states as problem-solvers with an informational advantage may improve EU policies, by adapting them to heterogeneous contexts and integrating local policy positions (Hooghe and Marks 2003: 235; Whitford 2007). This can facilitate context-sensitive solutions of the original policy problem at stake and increase the likelihood of effective and broadly accepted policy solutions at the point 
where the problem is most immediate (Keman 2000; Matland 1995). By introducing a bottom-up notion of member state discretion to Europeanization research, research on customization helps address salient questions.

First, rising levels of Euroscepticism and recent events such as Brexit highlight how European integration is increasingly perceived as a loss of sovereignty over national policies. The customization phenomenon relativizes the extent of this loss of control. It illuminates how member states use transposition as an opportunity to modify EU law and regain control. For example, Europeanization scholars could inquire how member states make use of different dimensions of customization to satisfy domestic interests during implementation (e.g., Thomson 2010). They could investigate to what extent more or less restrictive interpretations of EU rules enhance the legitimacy and acceptance of EU law 'on the ground' (Dörrenbächer 2017 LTHIS ISSUE: PUBLISHER TO ADD $\quad$ /UPDATE

\section{DETAILS AT PROOF>.}

Second, policy problems are only effectively resolved once EU policies are put into practice (Treib 2014). Legal compliance levels have a limited capacity to explain the practical application of EU law (Zhelyazkova et al. 2016). Conversely, the customization of EU policy is likely to result in different national practical application, enforcement and compliance practices (Versluis 2003, 2007). Customization patterns may prove a major missing link for gaining a better understanding of the EU's problem-solving capacity (Scharpf 1997). For example, customized restrictiveness and density could have a different impact on practical implementation. Studying restrictiveness helps Europeanization scholars to understand the freedom of maneuver national laws grant to implementing actors at the stage of practical implementation. This should generally influence the extent to which implementing actors can accommodate the ambiguous EU directives in a way that also fits local objectives. Conversely, adding more rules can complicate the practical implementation process. Whereas 
such conjectures need to undergo empirical scrutiny, our analyses showed that customized restrictiveness and density are distinct yet interrelated aspects of Europeanization processes.

Finally, the customization concept contributes to the fundamental theoretical debates surrounding the use of discretion in general multi-level implementation research (Thomann et al. 2016). Our results illustrate the interaction between centralized control and decentralized flexibility (Whitford 2007). Studies in comparative politics have long investigated the conditions under which national authorities increase or decrease the leeway of domestic implementing actors, mostly in the US federal system (Epstein and O'Halloran 1999; Huber and Shipan 2002). Especially customized restrictiveness could provide a useful yardstick for comparing discretionary freedoms across different member states and issue areas.

Much remains to be done to further explore such fine-grained Europeanization patterns, their explanation and implications for the practical application, effectiveness and acceptance of EU law. Future research should definitively strive for a more in-depth coding of customization, analyze its empirical relevance, and expand these insights to new policy areas. Our conceptualization and proposed measurement of customization should help Europeanization researchers to cumulatively paint a more complete picture of what Majone (1999: 309) famously termed the 'European experience'.

\section{Biographical notes}

Eva Thomann is a political scientist specialist in public policy and administration and currently a postdoctoral researcher at the Institute of Political Science, Heidelberg University, Germany.

Asya Zhelyazkova is a political scientist specialized in European Union politics and currently a research fellow at the School of Management of Radboud University Nijmegen, 
Netherlands.

\section{Address for correspondence}

Dr. Eva Thomann

Institute of Political Science, Heidelberg University

Bergheimer Straße 58

69115 Heidelberg

E-Mail: eva.thomann@ipw.uni-heidelberg.de

Dr. Asya Zhelyazkova

Institute of Management Research

Radboud University Nijmegen

Thomas van Aquinostraat 5

6525 GD NIJMEGEN

E-Mail: a.zhelyazkova@fm.ru.nl

\section{Acknowledgements}

We thank Tetty Havinga, Eva Heidbreder, Ellen Mastenbroek, Jale Tosun and the anonymous referees for their excellent comments.

Supplemental data for this article can be accessed at [link to supplementary material] 


\title{
Funding
}

This work was supported by the Swiss National Science Foundation under Grant number P2BEP1-162077.

\section{Endnote}

\begin{abstract}
${ }^{1}$ Additionally, formal intensity depicts domestic enforcement measures, administrative and procedural capacities that influence the probability of effectively achieving substantial requirements and the consequentiality of noncompliant behavior (Adam et al. 2015; Knill et al. 2012). Customization occurs during legal transposition. Changes in formal intensity are therefore only captured if the EU Directive explicitly contains respective provisions, and measured in their restrictiveness at the legal transposition stage.

${ }^{2}$ The member states vary in the number of EU provisions based on which customization is evaluated. For example, customization in Italy was evaluated for 95 Environment provisions, but only for 7 Environment provisions in Poland and Cyprus.
\end{abstract}




\section{References}

Adam, C., Hurka, S. and Knill, C. (2015) 'Four styles of regulation and their implications for comparative policy analysis', Journal of Comparative Policy Analysis: Research and Practice, DOI:10.1080/13876988.2015.1082262.

Adcock, R. and Collier. D. (2001) 'Measurement validity: A shared standard for qualitative and quantitative research', American Political Science Review 95(3): 529-546.

Angelova, M., Dannwolf, T. and König, T. (2012) 'How robust are compliance findings? A research synthesis', Journal of European Public Policy 19(8): 1269-1291.

Bauer, M.W. and Knill, C. (2014) 'A conceptual framework for the comparative analysis of policy change: Measurement, explanation and strategies of policy dismantling', Journal of Comparative Policy Analysis: Research and Practice 16(1): 28-44.

Davidson, N. (2006) 'Davidson review: Implementation of EU legislation', Retrieved online from

http://www.cabinetoffice.gov.uk/regulation/reviewing_regulation/davidson_review/index.asp [last accessed 7.3.2016].

Dörrenbächer, N. (2017) <THIS ISSUE: PUBLISHER TO ADD /UPDATE DETAILS AT PROOF>

Elmore, R.F. (1979) 'Backward mapping: Implementation research and policy decisions', Political Science Quarterly 94(4): 601-616.

Epstein, D. and O'Halloran, S. (1999) Delegating Powers: A Transaction Cost Politics Approach to Policy Making under Separate Powers, Cambridge: Cambridge University Press. 
Falkner, G., Treib, O., Hartlapp, M. and Leiber, S. (2005) Complying with Europe: EU harmonisation and soft law in the member states, New York: Cambridge University Press.

Franchino, F. (2007) The powers of the Union: Delegation in the EU, Cambridge: Cambridge University Press.

Hartlapp, M. and Falkner, G. (2009) 'Problems of operationalization and data in EU compliance research', European Union Politics 10(2): 281-304.

Heidbreder, E. (2017) <THIS ISSUE: PUBLISHER TO ADD /UPDATE DETAILS AT PROOF $>$ )

Hooghe, L. and Marks, G. (2003) 'Unraveling the central state, but how? Types of multi-level governance', American Political Science Review 97(2): 233-243.

Huber, J. and Shipan, C. (2002) Deliberate discretion? The institutional foundations of bureaucratic autonomy, Cambridge, UK: Cambridge University Press.

Jans, J.H., Squintani, L., Aragão, A., Macrory, R. and Wegener, B.W. (2009) "'Gold plating" of European environmental measures?, Journal of European Environmental Planning Law 6(4): 417- 435 .

Keman, H. (2000) 'Federalism and policy performance. A conceptual and empirical inquiry', in U. Wachendorfer-Schmidt (ed.), Federalism and political performance, London: Routledge, pp. 196-227.

Knill, C. and Tosun, J. (2012) 'Governance institutions and policy implementation in the European Union', in J. Richardson (ed.). Constructing a policy-making state? Policy dynamics in the EU, Oxford: Oxford University Press, pp. 309-333.

Knill, C., Schulze, K. and Tosun, J. (2012) 'Regulatory policy outputs and impacts: Exploring 
a complex relationship', Regulation and Governance 6(4): 427-444.

Lowi, T.J. (1972) 'Four systems of policy, politics, and choice', Public Administration Review 32(4): 298-310.

Majone, G. (1999) 'Regulation in comparative perspective', Journal of Comparative Policy Analysis: Research and Practice 1(3): 309-324.

Mastenbroek, E. (2005) 'EU compliance: Still a “black hole”?', Journal of European Public Policy 12(6): 1103-1120.

Mastenbroek, E. (2017) <THIS ISSUE: PUBLISHER TO ADD /UPDATE DETAILS AT PROOF>

Mastenbroek, E., van Voorst, S. and Meuwese, A. (2016) 'Closing the regulatory cycle? A meta evaluation of ex-post legislative evaluations by the European Commission', Journal of European Public Policy 23(9): 1329-1348.

Matland, R.E. (1995) 'Synthesizing the implementation literature: The ambiguity-conflict model of policy implementation', Journal of Public Administration Research and Theory 5(2): $145-174$.

Morris, R.KA. (2011) 'The application of the Habitats Directive in the UK: compliance or gold plating?', Land Use Policy 28(1): 361-369.

Padgett, S. (2003) 'Between synthesis and emulation: EU policy transfer in the power sector', Journal of European Public Policy 10(2): 227-245.

Richardson, J., Gustafsson, G. and Grant, J. (1982) 'The concept of policy style', in J. Richardson (ed.), Policy styles in Western Europe, Winchester: George Allen \& Unwin, pp. $1-16$. 
Sager, F., Thomann, E., Zollinger, C. and Mavrot, C. (2014) 'Confronting theories of European integration: A comparative congruence analysis of veterinary drugs regulations in five countries', Journal of Comparative Policy Analysis: Research and Practice 16(5):457474.

Schaffrin, A., Sewerin, S. and Seubert, S. (2015), Toward a comparative measure of climate policy output', Policy Studies Journal, DOI: 10.1111/psj.12095.

Scharpf, F. (1996) 'Negative and positive integration in the political economy of European welfare states', In G. Marks, F.W. Scharpf, P.C. Schmitter and W. Streeck (eds), Governance in the European Union, London: Sage, pp. 15-39.

Scharpf, F. (1997) 'Introduction: the problem-solving capacity of multi-level governance', Journal of European Public Policy 4(4): 520-538.

Schmidt, S.K. (2008) 'Beyond compliance: The Europeanization of member states through negative integration and legal uncertainty', Journal of Comparative Policy Analysis: Research and Practice 10(3): 299-308.

Shapiro, M. (1999) 'Implementation, discretion and rules', in J.A.E. Vervaele (ed.), Compliance and enforcement of European Community law, The Hague: Kluwer Law International, pp.27-34.

Steunenberg, B. (2007) 'A policy solution to the European Union's transposition puzzle: Interaction of interests in different domestic arenas', West European Politics 30(1): 23-49.

Thomann, E. (2015) 'Customizing Europe: Transposition as bottom-up implementation', Journal of European Public Policy 22(10): 1368-1387.

Thomann, E., Lieberherr, E. and Ingold, K. (2016) 'Torn between state and market: Private 
policy implementation and conflicting institutional logics', Policy and Society 35(1): 57-69.

Thomann, E. and Sager, F. (2017) <THIS ISSUE: PUBLISHER TO ADD /UPDATE DETAILS AT PROOF>

Thomson, R. (2010) 'Opposition through the back door in the transposition of EU Directives', European Union Politics 11(4): 577-96.

Toshkov, D. (2010) 'Taking stock: a review of quantitative studies of transposition and implementation of EU law', Institute for European Integration Research, Working paper No. $01 / 2010$

Treib, O. (2014) 'Implementing and complying with EU governance outputs', Living Reviews in European Governance 9(1).

Versluis, E. (2003) Enforcement matters. Enforcement and Compliance of European Directives in Four Member States, Delft: Eburon.

Versluis, E. (2007) 'Even rules, uneven practices: Opening the 'black box' of EU law in action', West European Politics 30(1): 50-67.

Vink, M.P. (2002) 'Negative and positive integration in European Immigration Policies', European Integration Online Papers 6(13).

Voermans, W. (2009) Gold-plating and double banking: an overrated problem?', in H. Snijders and S. Vogenauer (eds), Content and meaning of national law in the context of transnational law, Munich: Sellier European Law Publishers, pp. 79-88.

Whitford, A. (2007) 'Decentralized policy implementation', Political Research Quarterly 60(1): $17-30$. 
Windhoff-Héritier, A. (2001) Differential Europe: the European Union impact on national policymaking. Oxford: Rowman \& Littlefield.

Zhelyazkova, A. (2013) 'Complying with EU Directives' requirements: the link between EU decision-making and the correct transposition of EU provisions', Journal of European Public Policy 20(5): 702-721.

Zhelyazkova, A, Kaya, C., and Schrama. R. (2016) 'Decoupling practical and legal compliance: Analysis of member states' implementation of EU policy', European Journal of Political Research 55(4): 827-846. 


\section{Figures}

Figure 1: Customized restrictiveness and density in 27 member states, both policy areas

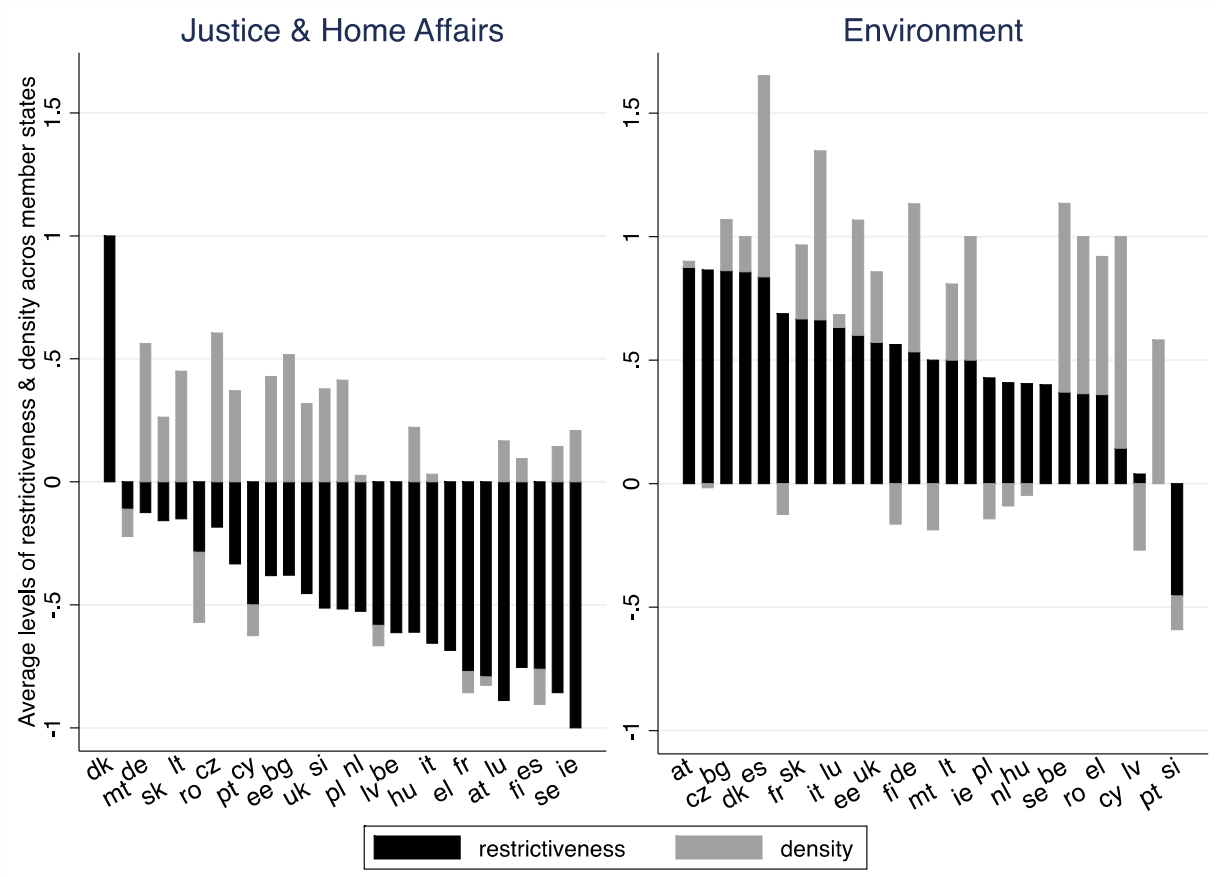

Figure 2: customized restrictiveness across member states for compliant national laws

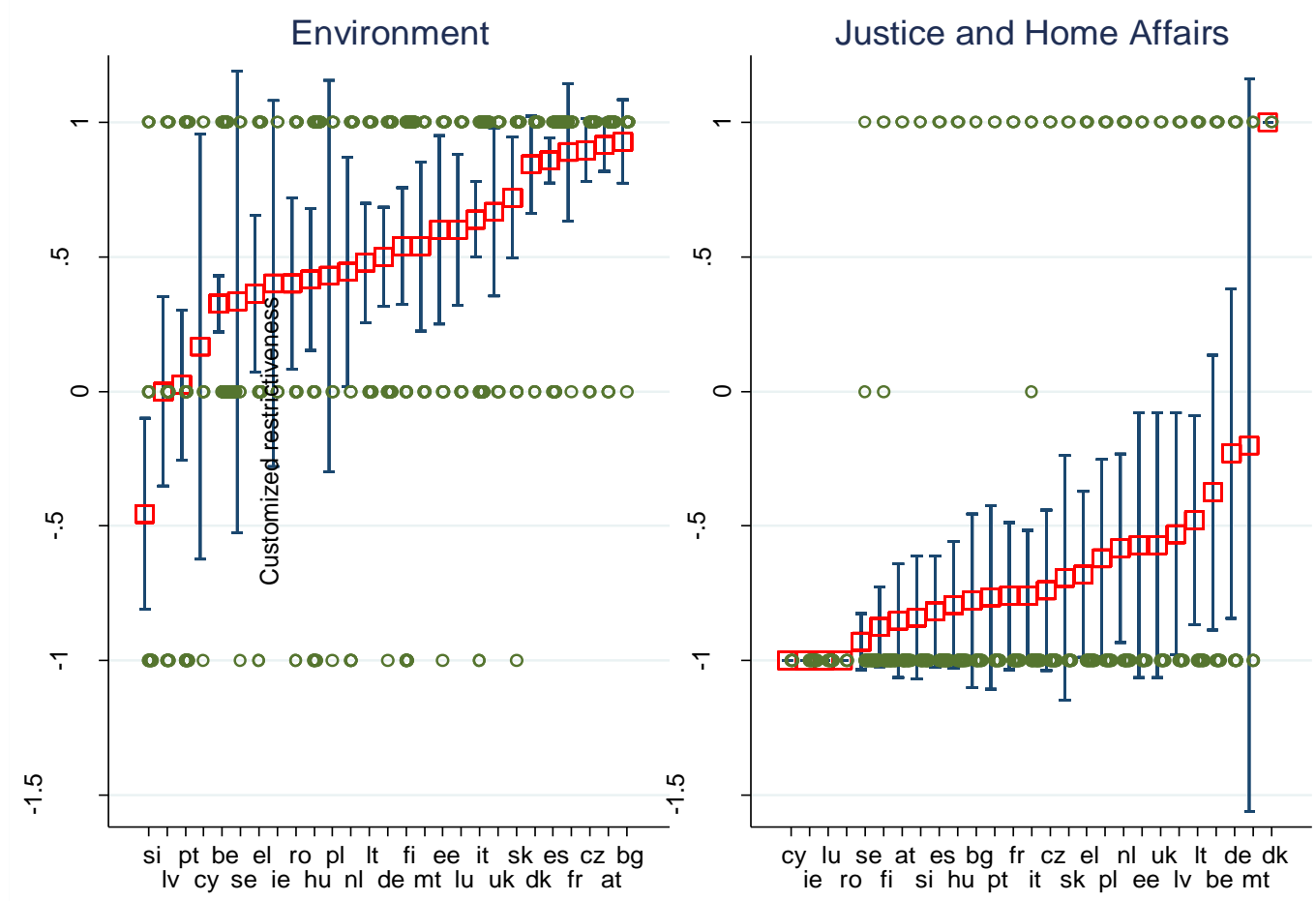

Legend $:$ Bars $=$ customized restrictiveness, capped lines $=$ confidence intervals, hollow circles $=$ individual cases. 